\title{
MICRORADIOGRAPHIC STUDY OF THE INTERVERTEBRAL BRIDGES IN ANKYLOSING SPONDYLITIS AND IN THE NORMAL SACRUM*
}

\author{
BY \\ R. J. FRANÇOIS \\ From the Research Laboratory of Orthopaedic Surgery (Prof. P. Lacroix), University of Louvain, Belgium
}

The present knowledge of the pathology of ankylosing spondylitis is based on clinical radiology, on the macroscopic study of macerated vertebrae, and on histological studies mainly of decalcified material (Van Swaay, 1950; Forestier, Jacqueline, and Rotes-Quérol, 1951; Aufdermaur, 1954; Engfeldt, Romanus, and Ydén, 1954; Cruickshank, 1956; Ott and Wurm, 1957). An important step in the development of the syndesmophyte, that is the intervertebral bridge in ankylosing spondylitis, is the calcification of the outer part of the intervertebral disk. We therefore looked for a method that would allow the study of undecalcified material and that would provide a link between the methods used up to now. Such a method is microradiography.

In children the sacral vertebrae are separated bones, like the other vertebrae. Sacralization starts about the age of 15 . Jacobson and Driver (1932) have published statistical and histological data on this subject. However, the most extensive study is that of Schwabe (1933). So far as the vertebral bodies and disks are concerned, fusion is first obtained by bony bridges in the outer layers of the annulus fibrosus, as is the case in ankylosing spondylitis. In order to understand the latter pathological process, it might be interesting to refer to the normal ossification of intervertebral disks in the sacrum.

\section{Clinical Data}

\section{Material and Methods}

Tissue was obtained from one case of ankylosing

* Paper given to the Heberden Society on October 3, 1964. A report of this meeting was published in the March, 1965, issue of the Annals, and the discussion which followed appears in vol. 24, p. 179. spondylitis and from three control subjects. The patient with ankylosing spondylitis was a male who started complaining of pain in the buttocks at the age of 33 . He later suffered from painful stiffness of the spine, especially in the early morning, and from iritis. The erythrocyte sedimentation rate was elevated. Radiographs showed a bilateral sacro-iliitis with erosions and sclerosis, and later a complete bony fusion; there were dorsal and lumbar bony bridges. The patient was also suffering from chronic bronchitis. One year before his death, he had a bout of haemorrhagic proctitis; thereafter he showed a nephrotic syndrome. He died rather suddenly, probably because of pulmonary insufficiency following another respiratory infection. Amyloid deposits were found at autopsy. The spinal column was removed from the eighth dorsal to the second sacral vertebra. A sagittal and a coronal slice of $\pm 4 \mathrm{~mm}$. thickness were isolated.

The three control subjects, aged 38,45 , and 54 died, respectively from aplastic anaemia, pulmonary embolism and cerebral injury.

\section{Microradiography and Histology}

The bone fragments were embedded in methyl methacrylate from Union Chimique Belge, after treatment with ethanol or neutral formol, methanol, chloroform, and toluol. The pieces were sawn with a GHI Thin sectioning machine from Hamco, Rochester (N.Y.), in slices of about $100 \mu$ thickness.

Microradiographs were made with a BE 50-20 Baltograph from Balteau, Liège, using Eastman Kodak 649 GH spectroscopic plates.

A histological picture was obtained with methylene blue by $20 \mathrm{~min}$. surface staining of the undecalcified slices. 


\section{Results}

\section{Control Intervertebral Disks}

Before showing the pictures of intervertebral bridges, it might be useful to remember the microradiographic appearance of the discal side of a control lumbar vertebra (Fig. 1). In an $x$-ray picture, the upper limit of a vertebral body is seen to be built up by cancellous bone and by the deeper, calcified part of the discal fibrocartilage.* Can-

* We consider the disk in its whole as a fibrocartilage. Some juxtavertebral parts of it look like hyaline cartilage, other parts look like tendon; there is no sharp demarcation between these two different aspects of the disk. cellous bone consists of parallel layers of calcified tissue containing osteocytes in a regular arrangement. Calcified fibrocartilage is whiter, that means richer in calcium salts, and is pitted with larger "holes" of variable size and outline. The amount of calcified cartilage is also quite variable; usually there is more calcified tissue at the periphery of the disk, and much less in the centre.

\section{Intervertebral Bridges in Ankylosing Spondylitis}

The successive stages of development of pathological intervertebral bridges in ankylosing spondylitis will be described.
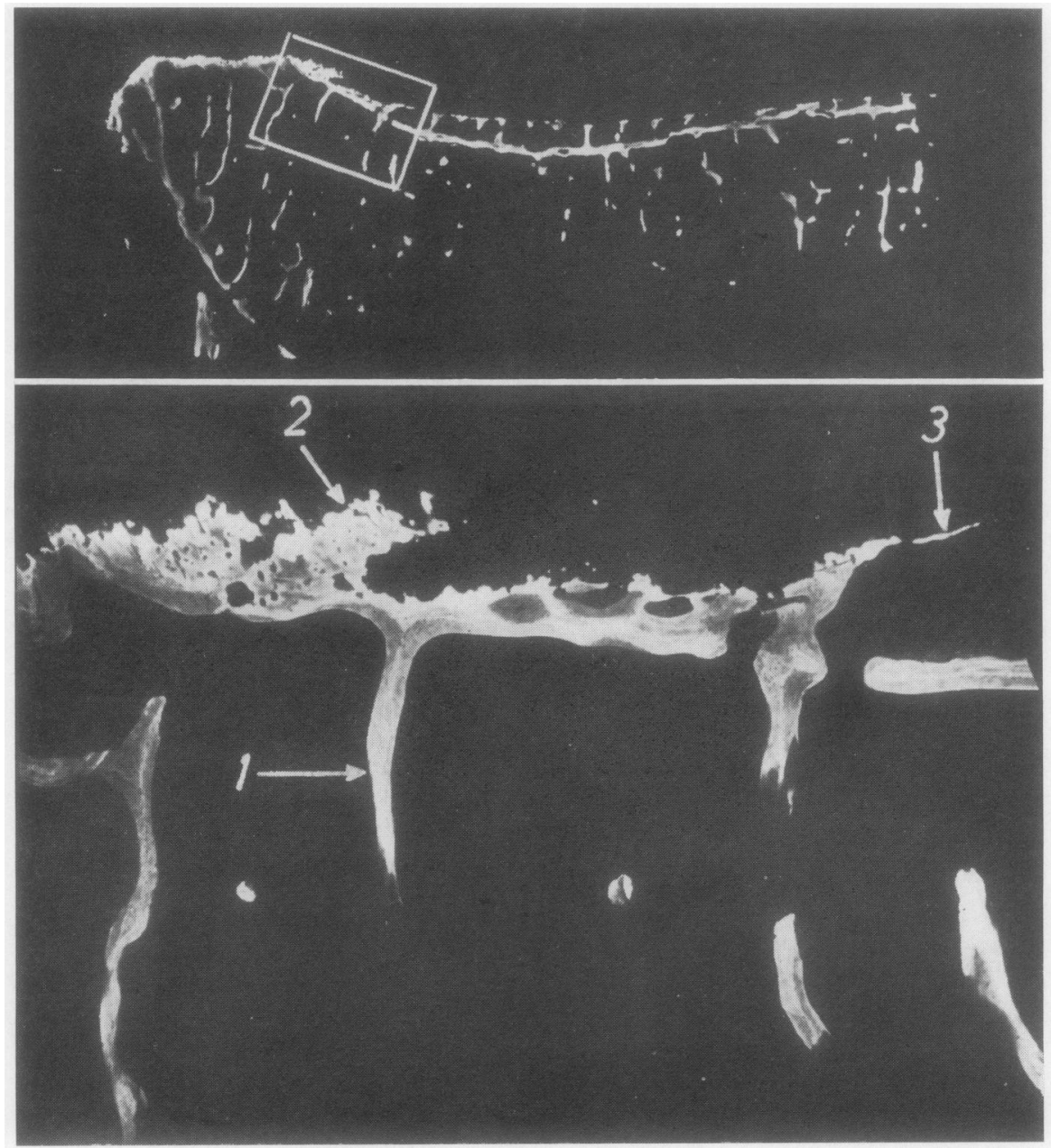

Fig. 1.-Control lumbar vertebra.

(a) Microradiograph of anterior and upper part of a sagittal slice in a lumbar vertebra from a control subject aged 45 . $\times 10$.

(b) Detail from $(a)$. This area consists mainly of cancellous bone, with its parallel layers of osteocytes embedded in calcified bone matrix. The cancellous bone is covered by calcified fibrocartilage. 1 : cancellous bone; 2 : rather thick calcified tissue with the characteristics of hyaline cartilage; 3: calcified cartilage reduced to a narrow strip. $\quad \times 60$. 

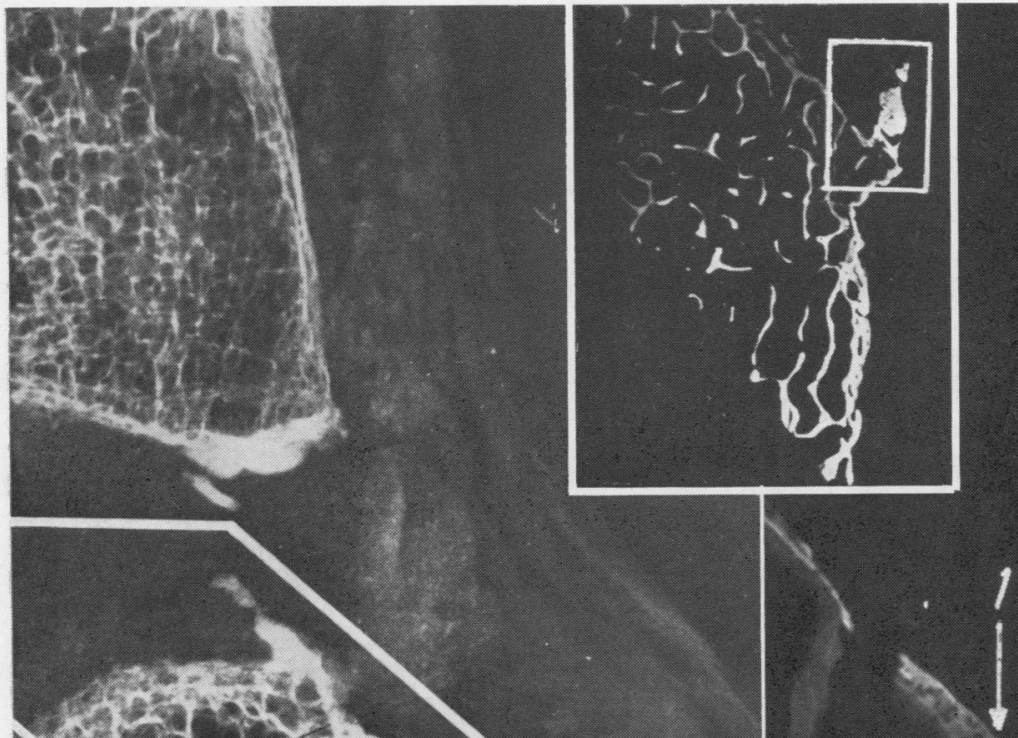

(a) Microradiograph of slice cut in region delineated in Fig. 2. $\times 4 \cdot 5$.

(b) Detail from $(a) . \quad \times 35$.

1: normal calcified fibrocartilage.

2: abnormal area of calcified fibrocartilage.

3: resorption cavity.

Fig. 4.-Ankylosing spondylitis.

Microradiograph of another $100 \mathrm{u}$ slice from the same syndesmophyte as in Figs 2 and 3. $\times 60$.

1: calcified fibrocartilage.

2: resorption cavity.

3: bone tissue.

An early stage is encountered dorsally in the L5-S1 disk (Figs 2, 3, and 4). The syndesmophyte consists mainly of calcified cartilage which is going to be replaced by bone tissue. Indeed, as calcified cartilage has no blood vessels and is not well suited for diffusion, it cannot grow beyond a certain limit or it must be replaced by bone. This occurs, through resorption (Fig. $3 b$ ) and deposition of bone layers on the inside of the resorption cavity (Fig. 4).

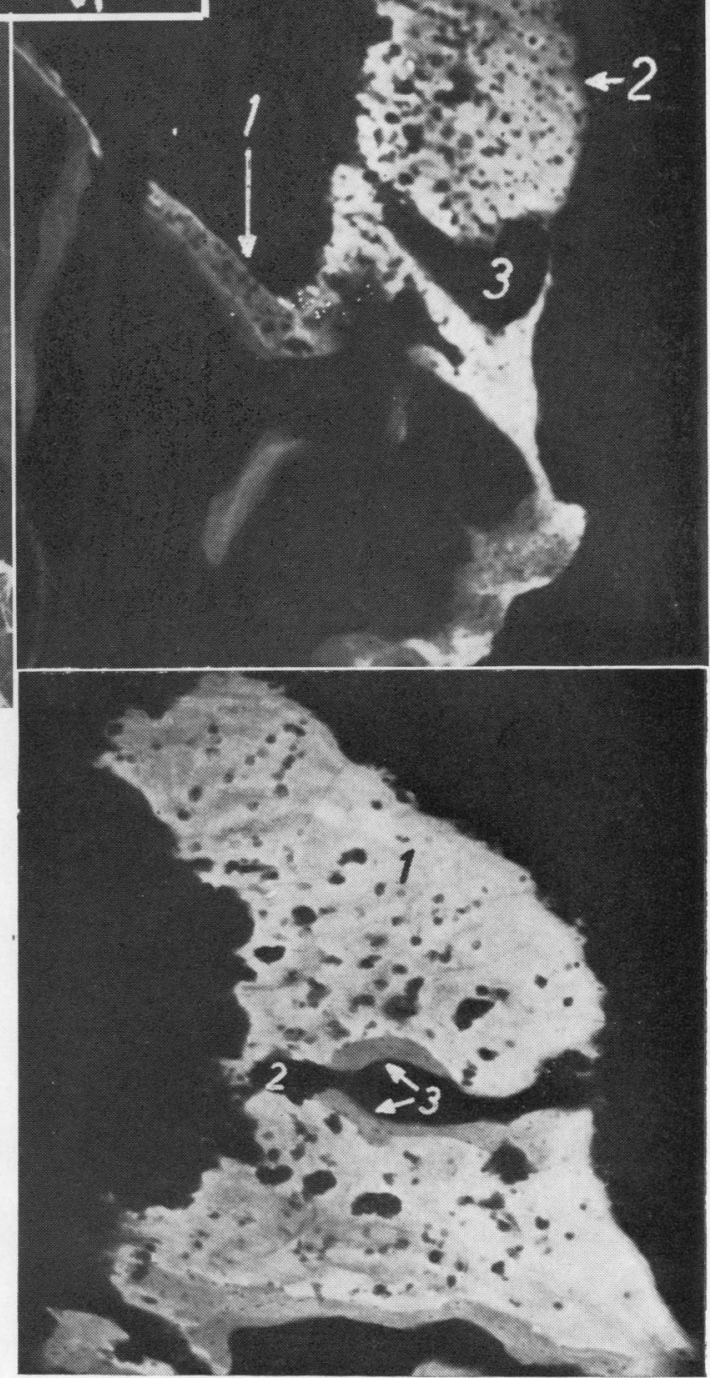

4

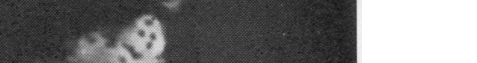

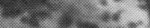
$3-x^{2} \cdot x^{2}$

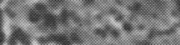

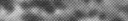
$3 .+-1$

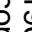
每 
Subsequent stages with complete bridges are seen at the D11-D12 disk. The posterior bridge (Figs 5 and 6) has a rather complicated structure. The calcified cartilage, which is partially replaced by bone, has two different appearances. Near the vertebrae, the calcification is more homogeneous, and is striated. At some distance from the vertebrae, the calcification is much less homogeneous, it looks moth-eaten, and there is no striation. From the comparison with the histological picture (Fig. 6b) it appears that the difference between the more and the less homogeneous calcified tissues is the result not only of more or less complete calcification but also of different fibre direction. It is clear that some fibres are cut along their longitudinal axis, whereas others are cross-cut. This might be expected, considering the structure of the disk. Lastly, it will be noted that there is also an amorphous calcium deposit, and that the methylene blue stain allows the differentiation of calcified from non-calcified structures.

The anterior bridge of the same disk illustrates the next step where bone has extensively replaced the calcified fibrocartilage, of which a few islets remain (Fig. 7). Later on, the bridge becomes completely bony, with only a narrow rim of calcified fibrocartilage on its inner surface at the insertion of the non-calcified fibres. In large disks, bone gradually replaces the two half bridges before they join; only the growing fronts of both halves consist of calcified fibrocartilage.

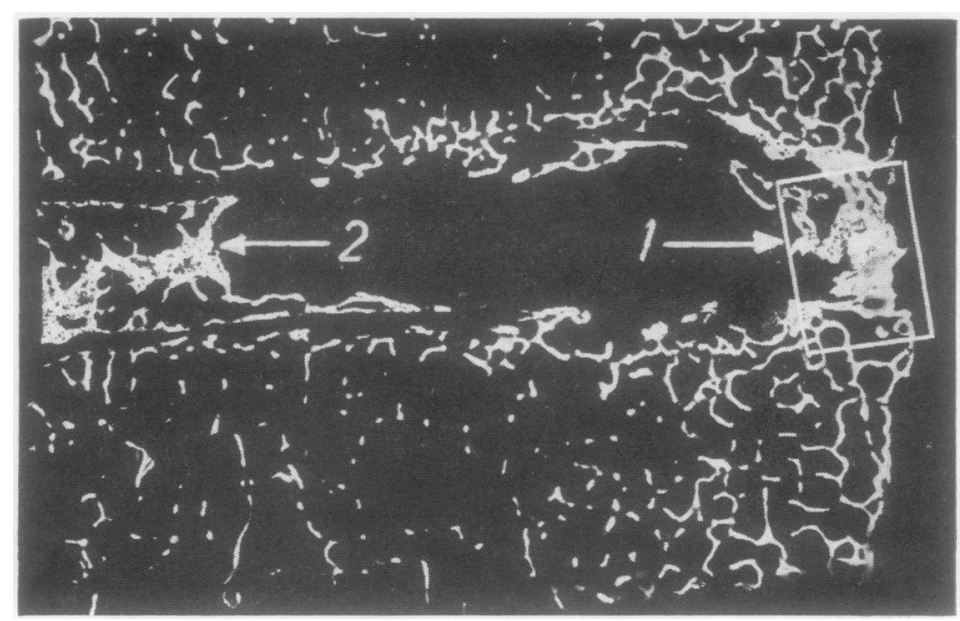

Fig. 5.-Ankylosing spondylitis.

Microradiograph of posterior part of D11-12 disk. $\times 9$. 1: complete intervertebral bridge. 2 : central ossification.

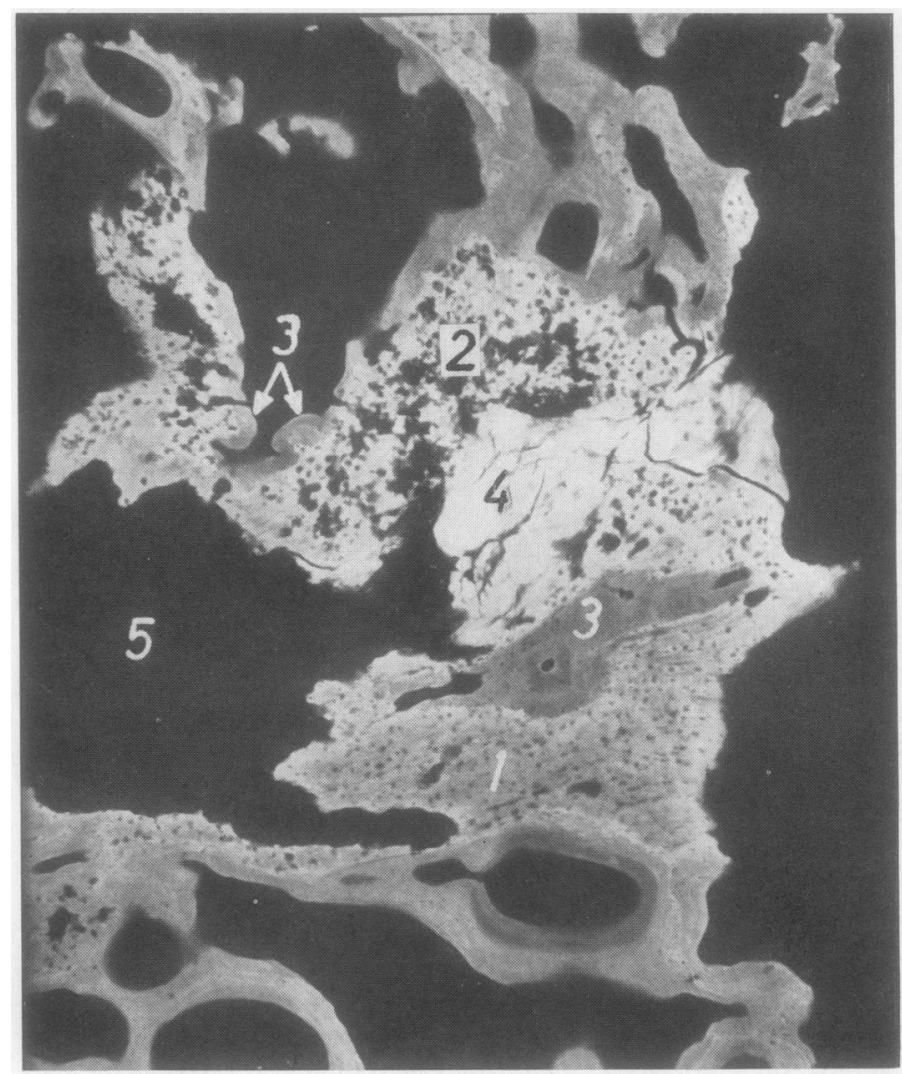

Fig. 6. Ankylosing spondylitis, showing correlation between microradiographic and histological pictures.

(a) Microradiograph of rectangle from Fig. 5.

1: striated calcified fibrocartilage: 2: non-striated calcified fibrocartilage; 3 : bone; 4: amorphous calcium deposit; 5 : noncalcified fibrocartilage. 
(6b) Methylene blue staining of the same slice as in $(a)$.

$1,2,3,4,5$ as in $(a)$; 6 : posterior longitudinal ligament. $\times 60$.

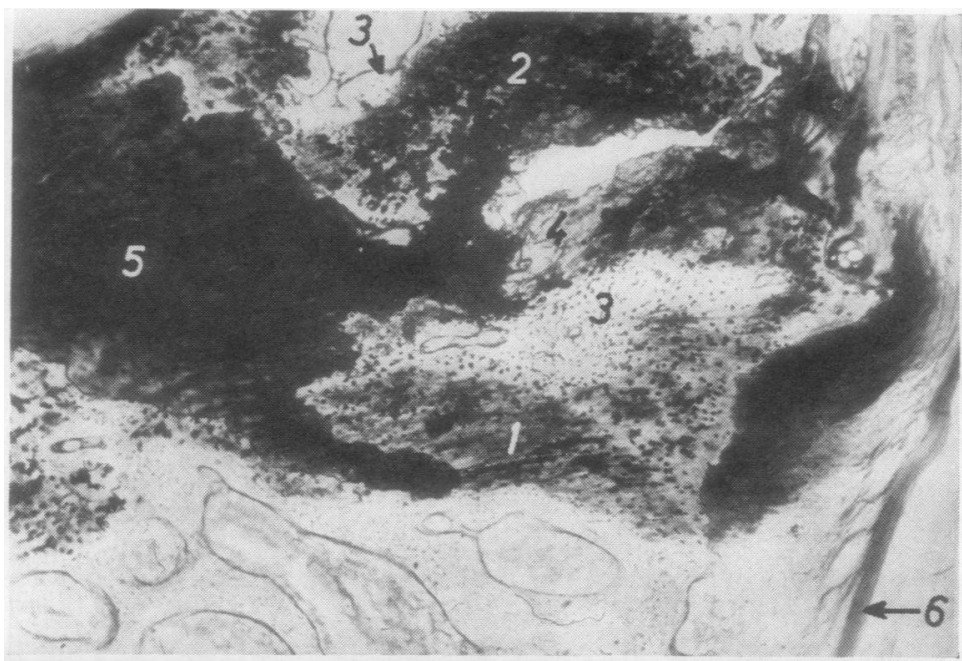

$6 b$
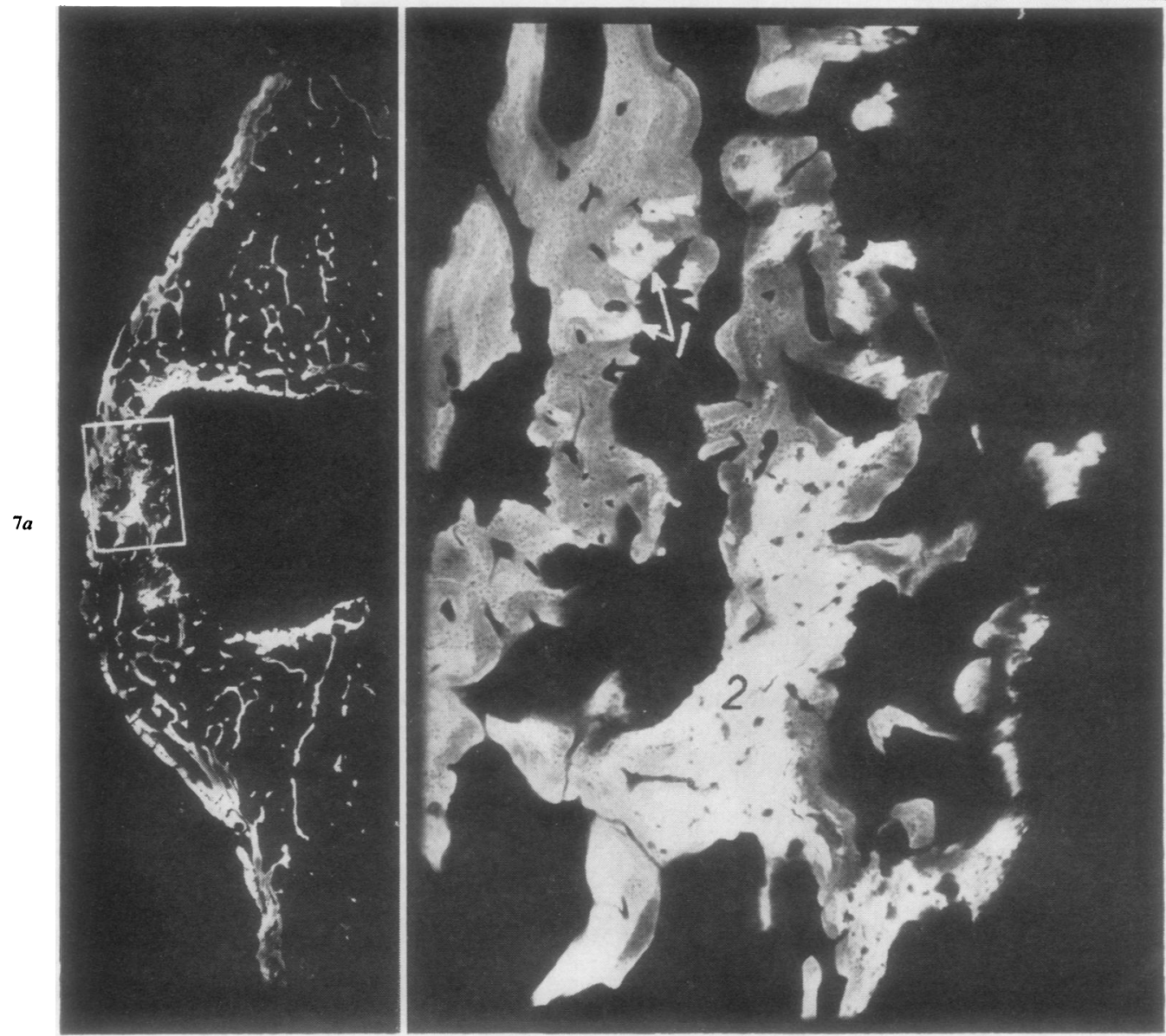

Fig. 7.-Ankylosing spondylitis. (a) Microradiograph of anterior syndesmophyte of D11-12 disk. The bridge is built up mainly of bone; there are a few remnants of calcified fibrocartilage. $\times 4 \cdot 5$. (b) Detail from $(a) .1$ and 2 : calcified fibrocartilage. $\times 35$. 

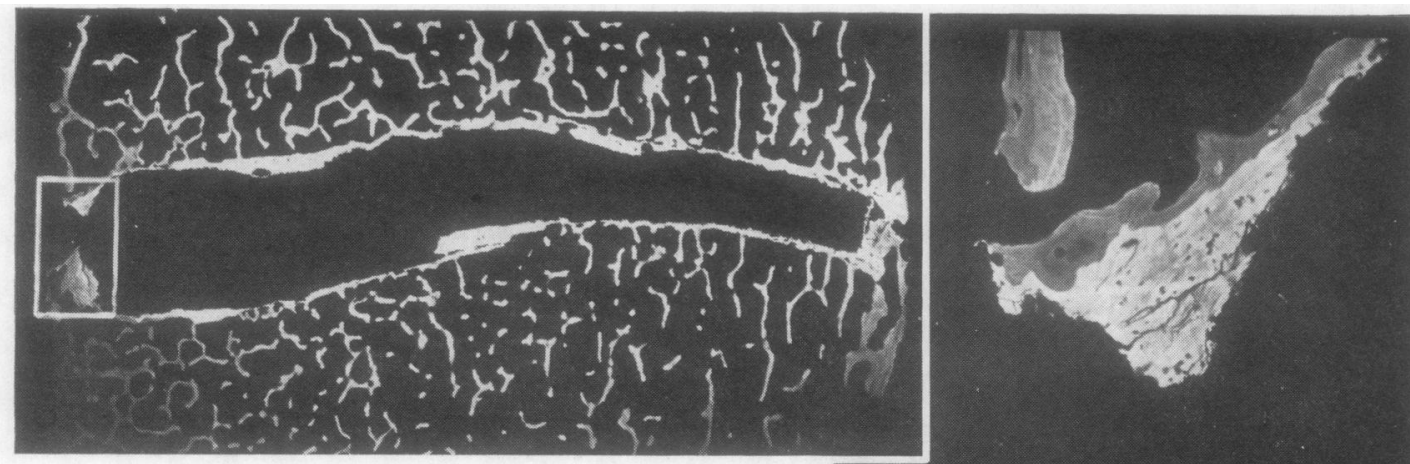

Fig. 8.-Control sacrum.

(a) Microradiograph of sagittal section of a first sacral disk of a control subject aged 55. Anterior is to the right. $\times 3 \cdot 5$

(b) Detail from (a). Incomplete intervertebral bridge consisting mainly of calcified fibrocartilage (1) with some bone replacement (2).

Compare Figs 3 and $4 . \times 30$

\section{Intervertebral Bridges in the Normal Sacrum}

As can be seen from Figs 8, 9, and 10, the intervertebral bridges in sacral disks start in the outer layers of the annulus fibrosus, as in ankylosing spondylitis. Obviously, the development of bony bridges follows the same stages as in ankylosing spondylitis: calcification of the fibrocartilage, resorption of the latter, and deposition of bone lamellae in the resorption cavities. Another similarity is the very slow evolution with prolonged periods of arrest.

\section{Discussion}

Our results are in agreement with those of Collins (1949) Van Swaay (1950); Forestier and others (1951), and Ott and Wurm (1957), who consider the syndesmophytes of ankylosing spondylitis to be the consequence of a kind of endochondral ossification. Aufdermaur (1954) also states that, in some cases, calcification of cartilage precedes the ossification. Although we think destructive and inflammatory changes are present in ankylosing spondylitis, we do not regard all syndesmophytes as the reparative phase of a subacute osteitis as do Engfeldt and others (1954) and Cruickshank (1956).

Schwabe (1933) has described the peripheral discal bridging in the sacrum as the result of a double process; a kind of endochondral ossification in the outer layers of the annulus fibrosus, and periosteal bone apposition in the deeper layers of the anterior longitudinal ligament. Our findings corroborate the former point. The role played by peri-

osteal bone apposition in the anterior sacral bridges, and in the bridges of ankylosing spondylitis, is to be investigated in a larger series of cases.

The original contribution of this paper lies in the use of microradiography, which shows clearly what is and what is not calcified, and in the demonstration of the similarity between a pathological and a normal discal ossification.

Differences, however, should not be overlooked. Inflammatory and destructive changes have not been described in normal sacra, but are part of the pathological changes in ankylosing spondylitis; for example, blood vessels were seen in eight out of the ten disks in the present case, and destructive changes were seen radiologically or histologically in at least four disks.

How may the observed similarity be interpreted?

As a first hypothesis, ankylosing spondylitis is merely the extension to the rest of the spine of a 


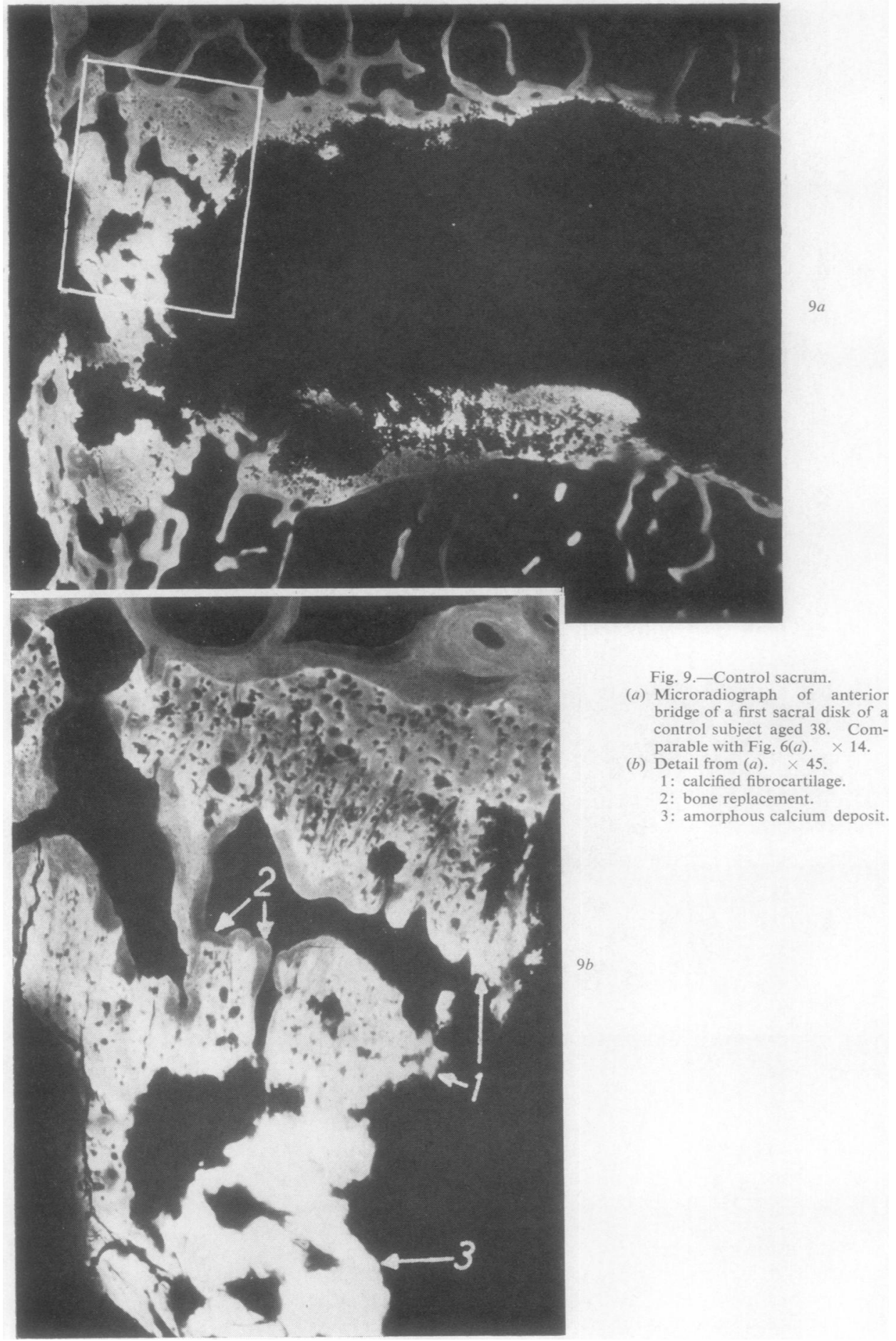



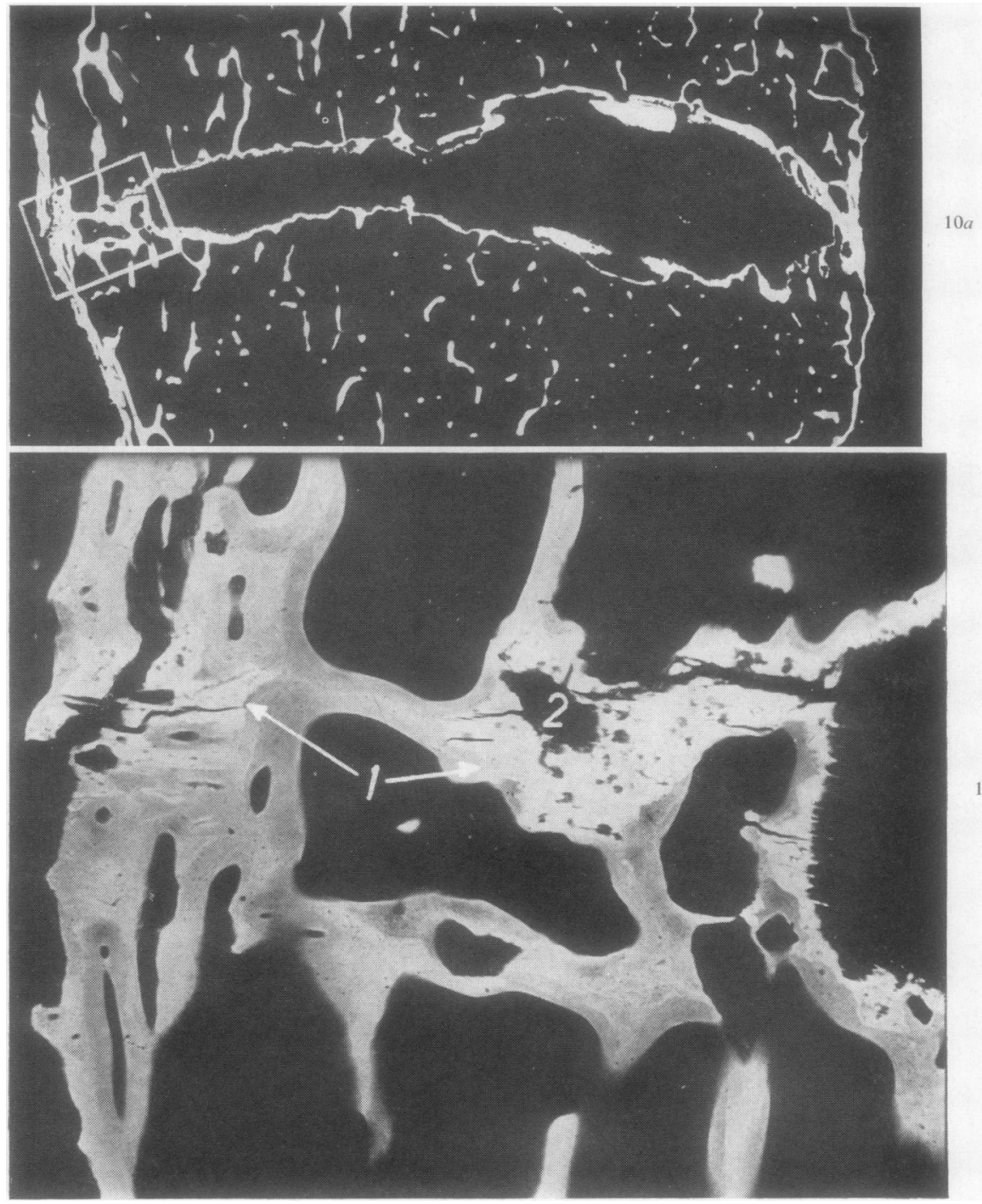

Fig. 10.-Control sacrum.

(a) Microradiograph of sagittal slice of a first sacral disk of a control subject aged 45. Anterior is to the left. $\times 5$.

(b) Enlargement of anterior bridge, built up mainly of bone, with remnants of calcified fibrocartilage (1) and resorption cavities (2). Compare with Fig. $7 . \quad \times 35$.

process normally located in the sacral vertebrae. Ankylosing spondylitis could be a metabolic disease of fibrocartilage; an inborn error of metabolism would account for the known partially hereditary character of the disease. However, sacralization does not give rise to symptoms, does not elevate the erythrocyte sedimentation rate, and is not accompanied by vascularization or destructive lesions.

A second hypothesis is that local inflammation initiates the ossification. But many authors saw no inflammatory changes in their material. Either the inflammatory changes are evanescent, or they are not a constant feature in this disease. And why then are there conditions, such as adult rheumatoid arthritis, in which inflammatory changes are present in the spine without the occurrence of syndesmophytes?

At the present moment, no pathogenic hypothesis 
can explain all the clinical and pathological features of ankylosing spondylitis. We must resort to a completely new hypothesis, or we must admit a combination of at least two causal factors, one predisposing, allowing ossification of any disk, and one local, initiating the process at a particular level.

\section{Summary}

Five dorsal and five lumbar intervertebral disks obtained at the autopsy of a case of ankylosing spondylitis, and three sacra from control subjects aged 38,45 , and 54 years have been studied by microradiography. The same calcification and ossification processes are involved in the development of both the syndesmophytes of ankylosing spondylitis and the intervertebral bridges of the normal sacrum.

I am very grateful to Dr. A. Dhem, who taught me the methods used in this study. I thank Prof. Dr. T. G. Van Rijssel and Dr. C. F. Hollander, of the Department of Pathology of the University Hospital, Leyden, for the specimen of ankylosing spondylitis, and Dr. J. Lauwereyns, Dr. V. Desmet, and Dr. F. Meersseman of the Pathological Departments of the University Hospitals, Louvain, for the control material.

\section{REFERENCES}

Aufdermaur, M. (1954). "Spondylite ankylosante. I. Anatomie pathologique." Documenta Rheumatologica, no. 2. Geigy, Basel.

Collins, D. H. (1949). "The Pathology of Articular and Spinal Diseases." Arnold, London.

Cruickshank, B. (1956). J. Path. Bact., 71, 73.
Engfeldt, B., Romanus, R., and Ydén, S. (1954). Ann. rheum. Dis., 13, 219.

Forestier, J., Jacqueline, F., and Rotes-Quérol, J. (1951). "La spondylarthrite ankylosante." Masson, Paris.

Jacobson, A. S., and Driver, H. (1932). Beitr. path. Anat., 90, 233.

Ott, V. R., and Wurm, H. (1957). "Spondylitis Ankylopoetica." Steinkopff, Darmstadt.

Schwabe, R. (1933). Virchows Arch. path. Anat., 287, 651.

Van Swaay, H. (1950). "Spondylosis ankylopoëtica. Een Pathogenetische Studie." Ijdo, Leyden.

\section{Etude microradiographique des travées intervertébrales dans la spondylarthrite ankylosante et dans le sacrum normal}

\section{RÉSUMÉ}

Cinq disques intervertébraux dorsaux et cinq lombaires obtenus à l'autopsie d'un cas de spondylarthrite ankylosante, ainsi que trois sacrums des témoins âgés de 38,45 et 54 ans, ont été étudiés microradiographiquement. Les mêmes processus de calcification et d'ossification sont impliqués dans le développement tant des syndesmophytes de la spondylarthrite ankylosante que des travées intervertebrales du sacrum normal.

Estudio microradiográfico de los puentes intervertebrales en la espondilartritis anquilosante y en el sacro normal

\section{SUMARIO}

Cinco discos intervertebrales dorsales y cinco lumbares obtenidos a la autopsia de un caso de espondilartritis anquilosante y tres sacros de sujetos normales de 38,45 y 54 años de edad fueron estudiados microradiográficamente. Idénticos procesos de calcificación y de osificación intervienen en el desarrollo tanto de los sindesmofitos de la espondilartritis anquilosante como de los puentes intervertebrales del sacro normal. 